
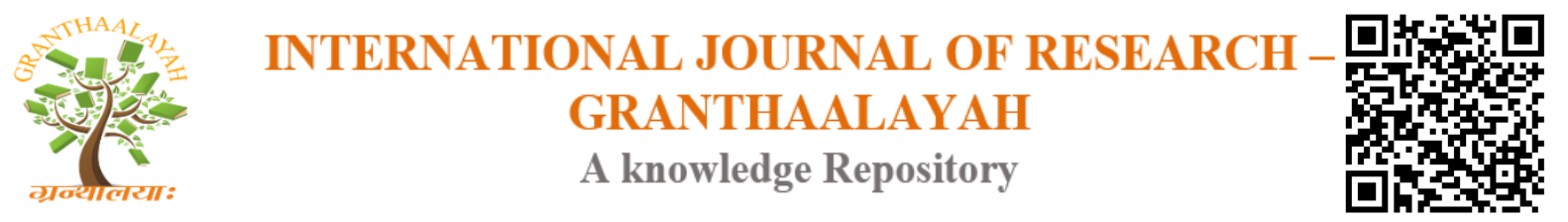

Science

\title{
PHYSICO-CHEMICAL MONITORING OF LAKE WATER DURING IDOL IMMERSION
}

\author{
Bharti Dwivedi ${ }^{1}$, Dr. Suchitra Banerjee ${ }^{2}$ \\ ${ }^{1}$ Govt. Subhash School for Excellence Bhopal, India \\ ${ }^{2}$ Institute for Excellence in Higher Education IEHE Bhopal, India
}

\begin{abstract}
The present study concerns on physicochemical monitoring of the water quality nature and the extent of pollution in lake due to idol immersion. Pre-immersion and post immersion samples were collected from lake and analyzed for various water quality parameters such as $\mathrm{pH}$, turbidity, total dissolve solid (TDS), total solid (TS) total suspended solid (TSS), conductivity phosphate, dissolved oxygen (DO), BOD, COD and oil \& grease.

The results were compared with standards prescribed by WHO and ISI. From the study, it has been found that the values of these parameters significantly increased during the immersion period and the declined in post immersion period. However the general trend observed was: immersion> Post immersion> pre immersion. The article focused on the main pollution which is caused by plaster of Paris idols and chemical paints by idol immersion during Ganesh festival.
\end{abstract}

Keywords: Physico-Chemical Characteristics; Idol Immersion; Water Quality Assessment Parameter.

Cite This Article: Bharti Dwivedi, and Dr. Suchitra Banerjee. (2018). "PHYSICO-CHEMICAL MONITORING OF LAKE WATER DURING IDOL IMMERSION." International Journal of Research - Granthaalayah, 6(7), 159-163. 10.29121/granthaalayah.v6.i7.2018.1294.

\section{Introduction}

Our earth seems to be unique among the other known celestial bodies. It has water which cover three fourth of its surface and constitute 60-70 wt\% of living world. Water is one of the most essential component of life. Life, both animals and plants is impossible without water so there is need to protect the water resources from pollution and prevent the depletion of water resources. Pollution of water resources is a major problem in today' era.

India is land of festivals. Festivals are an integral part of rich and diverse cultural heritage of India. Traditionally Ganesha idols were sculpted out of earth and after work shipping returned back to earth by immersion. Idol immersion activities during festival are adding to pollution load of water bodies. Now days the materials used for making idols has led to use of non-biodegradable material like plaster of Paris thermocol, clay, synthetic colours etc. Which polluted water and change its 
nature. chemical paints used to paints these idols contain heavy metals which bio magnify along food chain. Floating material released through idol in the lake or river after decomposition result in eutrophication (Leland: 1991)

\section{Materials and Method}

For present study, water samples were collected from surface area of lake during morning hours at the site of immersion.

Pre immersion samples were collected a week prior to immersion activity. During the immersion period immersion samples were collected whereas post immersion samples were collected three weeks after the completion of immersion activities. The samples were collected from the idols immersion site and analyzed for various water quality parameters viz PH, DO, TDS as per standard methods (APHA 1995). PH was analyzed using PH meter, Turbidity was estimated using turbidity meter and conductivity water estimated by conductivity meter total hardness was analyzed by titrimetric EDTA method. COD was determined using. potassium dichromate open reflux method Do-samples were fixed on the sport and analyzed immediately by Winkler's method with azide modification.

\section{Preparation of TSS, TDS, TS Samples}

Well mixed sample was filtered through a weighed standard galls fiber filter. The residue retained on the filter was tried to constant weight to estimate TSS. While the filtrate obtained was evaporated to dryness till constant weight obtained in order to estimate TDS. The sum total of TSS and TDS gives TS value.

\section{Observation}

\section{Turbidity}

Turbidity of water found high during post idol immersion period. While it was observed low during the pre immersion.respectively. Turbidity of water during post-immersion period was found high 27 NTU while it was observed low during the pre-immersion 02 NTU.

\section{Temperature}

$\mathrm{A}$ in the present study water temperature was found be $32^{\circ} \mathrm{C}-32.5^{\circ} \mathrm{C}$; The studies showed the increased temperature of lake speed up the chemical reaction and biological activity that reduces the solubility of gases in water (Murugesanetal 2004) The value of temperature during the preimmersion and post-immersion period it was found 32.2 and $32.5^{\circ} \mathrm{C}$

\section{Total Alkalinity}

Total alkalinity of water is mainly due to presence of cations of calcium, magnesium, potassium and sodium. It is also due to combined carbonate or bicarbonate or occasionally hydroxide. Analysis of water showed the higher alkalinity which was due to idol immersion during postimmersion period. Total alkalinity was found high $230.0 \mathrm{mg} / 1$ during post-immersion while it was comparatively low $160.0 \mathrm{mg} / 1$ during pre-immersion period. 


\section{Conductivity}

Conductivity measure the water's ability to conduct electricity which provides measure of what dissolved in water higher conductivity values shows that there are more chemicals dissolve in the water. Value of conductivity is higher during idol immersion period.

\section{pH}

The $\mathrm{pH}$ value of water is an important indication of its quality. The $\mathrm{pH}$ was analyzed by $\mathrm{pH}$ meter and it is found that values of.ph is increase in immersion period $\mathrm{pH}$ of water found alkaline. It was 8.7 during the pre-immersion while 8.1 during post-immersion period.

\section{Total Suspended Solid (Tss)}

Total suspended solids highly increase during idol immersion period and then decrease in the post immersion. Significant changes in value of. Total suspended solid was found $30.0 \mathrm{mg} / 1 \mathrm{during}$ pre-immersion period while it was $160.0 \mathrm{mg} / 1$ post immersion

\section{TDS}

TDS increased during immersion period which declined in post immersion period.

\section{T.S.}

Total solids increase during immersion and post immersion period.

\section{Total Hardness}

During idol immersion activity total hardness in lake water was found to be increase with higher values Hardness is commonly reported aspect of water quality .calcium and magnesium are the main principal hardness causing cations .Hardness (especially calcium content ) has increased significantly during idol immersion and con down to the original level even after wards this shows that the water quality has deteriorated during idol immersion and continues so for a long time increase in hardness continus to increase even post immersion

\section{Biological Oxygen Demand (Bod)}

BOD is direct measure of $\mathrm{O}_{2}$ requirement and indirect measures of biodegradable organic matter. The increased value of BOD was again due to idol immersion.that significantly increased 6.08 $\mathrm{mg} / 1$ during post-immersion period.

\section{Dissolved Oxygen}

Dissolved oxygen is also one of the important factor of water quality which influences the biota present inside the lake water. Idol immersion adversely affects the D.O. During this study it observed low in lake decrease in dissolved oxygen was due to idol immersion activity and rise in temper. Dissolved oxygen was observed low $4.05 \mathrm{mg} / 1$ during post-immersion period while it was $9.31 \mathrm{mg} / 1$ during pre-immersion period.

\section{Cod (Chemical Oxygen Demand)}

Chemical oxygen demand (COD) indicates the extent of chemical pollution mainly from chemical used during idols painting. The COD values observed maximum during immersioni. High value of COD101.2 mg/1 was observed during the post-immersioperiod that was comparatively low 56.0 $\mathrm{mg} / 1$ during pre- 


\section{Total Calcium}

Values of total calcium were very high due to the idol immersion activity.

\section{Nitrates}

Value of nitrates were also increased. During immersion and post immersion period.

\section{Phosphate}

Phosphate is considered to be the most significant among the nutrients responsible for eutrophication of lake as it is primary initiating factor. Concentration of phosphate increase after idol immersion it may be due to deportion of ashes and chemical under religious activities.

\section{Heavy Metal}

Values of heavy metals leade and chromium are increase in immersion period and post immersion period thus they are components of paints by with idols all decorated.

\section{Oil and Grease}

The value of oil and grease increase due to oil paints for painting the idols and oil offering by the devotes during workship. Oil and grease of present in excess amount it interfere with areobic and anaerobic biological process atimmersion period. Oil and grease was observed high 0.79 mg/1.

\section{Results and Discussion}

Present study shows that water pollution due to idol immersion bring change in hydro chemical properties and cause damage to aquatic ecosystem. The value of physicochemical parameters show that water is highly polluted Turbidity, Chloride, total alkalinity, BOD, COD total hardness is three to five times higher than slandered unit. Value of dissolved oxygen is fearless than standard value which affects the aquatic flora and fauna adversely

\section{Conclusion}

Present study on "Physico-chemical monitoring of lake water during idol immersion" revealed that idol immersion activities have negative impact on water quantity of lake. Idol immersion every year has lead to an increase in amount of clay and sand which leads to sedimentation. The input of biodegradable and non-biodegrable substance denture lake water quality. Heavy metals contamination was found to higher in post idol immersion from permissible limit which hazards in living orgnism.

\section{References}

[1] Idol. Accessed on 29/5/2014, accessed from http:/dictionary. reference. com/browse/idol. 10.1163/1872-5287_bdr_sim_00041

[2] Reddy V.M., Kumar V.A. Effect of ganesh idol immersion on some water quality parameter of HussainSagar. Current Science, 1412-1413. 10.7598/cst2012.169

[3] Dhote S., Varghese B., Mishra S.M. 2001. Impact of idol immersion on water quality of twin lakes of Bhopal.Indian Journal of Environment Protection 21, pp.998-1005.

$10.15373 / 22778179 /$ feb2014/58 
[4] BhatN.A., Wanganeo R., Wanganeo A. 2012. Pollution Status of Bhoj Wetland before and after Immersion of Idols. 5(1), 154-156. 10.5897/ijfa14.0431

[5] The times of india. Idols' immersion adds to Ganga's pollution. Accessed on 30/05/2014, accessed from http: /timesofindia. indiatimes. com/city/patna/ Idols-immersion-adds-to Gangaspollution/articleshow/16964313. cms. $10.9790 / 3008-09240513$

[6] Bibicz, M. 1982. Heavy metal in the aquatic environment of some water bodies of the Lublin basin, Actuatic Hydrobiology, 24, 125-138. 10.1016/0048-9697(90)90013-k

[7] Handy R.D. 1993. The accumulation of dietary aluminium by rainbow trout oncorhynchusmykiss at high exposure concentrations. Journal of Fish Biology 42(4), 603-606. 10.1111/j.1095-8649. 1993.tb00363.x

*Corresponding author.

E-mail address: bhartidwivedi5@ gmail.com 